\title{
Laparoscopic liver resection and the learning curve: a 14-year, single-center experience
}

\author{
Xiujun Cai $\cdot$ Zheyong Li $\cdot$ Yale Zhang $\cdot$ \\ Hong Yu $\cdot$ Xiao Liang $\cdot$ Renan Jin • \\ Feng Luo
}

Received: 17 February 2013/ Accepted: 6 August 2013/Published online: 8 January 2014

(C) The Author(s) 2014. This article is published with open access at Springerlink.com

\begin{abstract}
Background Laparoscopic liver resection has not been widely used because of intraoperative bleeding. This problem should be solved with instruments and techniques that require a short learning curve.

Materials and methods The aim of this work was to present the technique used in our center to perform laparoscopic liver resection using the 'curettage and aspiration' technique with laparoscopic Peng's multifunctional operational dissectors and regional occlusion of inflow and outflow. We retrospectively analyzed patients who underwent a laparoscopic liver resection from August 1998 to August 2012, and collected the conversion rate, operating time, blood loss, hospitalization, bile leakage rate, bleeding
\end{abstract}

Electronic supplementary material The online version of this article (doi:10.1007/s00464-013-3333-5) contains supplementary material, which is available to authorized users.

\section{Cai $(\square)$}

Key Laboratory of Laparoscopic Technique of Zhejiang Province, Department of General Surgery, Sir Run Run Shaw Hospital, Institute of Minimally Invasive Surgery of Zhejiang University, Zhejiang University, No. 3, Qingchun Road East, Hangzhou 310016, China

e-mail: cxjzju@gmail.com

\section{Z. Li $\cdot$ Y. Zhang $\cdot$ R. Jin}

College of Medicine, Zhejiang University, Hangzhou, China

H. Yu $\cdot$ X. Liang

Department of General Surgery, Sir Run Run Shaw Hospital, Zhejiang University, Hangzhou, China

F. Luo

Department of Anesthesiology, Sir Run Run Shaw Hospital, Zhejiang University, Hangzhou, China rate, and other complications on a yearly basis and in total. We used SPSS software to analyze whether there was a significant difference, and summarized the learning curve of laparoscopic liver resection with various procedures.

Results We performed 365 cases of laparoscopic liver resection, including left hemihepatectomy, left lateral lobectomy, segmental hepatectomy, non-anatomic liver resection, right hemihepatectomy, and caudate lobectomy. The diseases included liver cancer, hepatolithiasis, liver hemangioma, focal nodular hyperplasia, liver abscess, and metastatic hepatic carcinoma. In total, 63 cases (17.20\%) were converted to open surgery because of severe adhesions, bleeding, or anatomical limitation. Mean blood loss was $370.6 \pm 404.0 \mathrm{ml}$; mean operating time was $150.8 \pm 73.0 \mathrm{~min}$; and mean postoperation hospitalization was $9.2 \pm 5.3$ days. There were four cases $(1.32 \%)$ with the complication of bile leakage and two cases of hemorrhage $(0.66 \%)$. No intraoperative or postoperative deaths occurred. After finishing 15-30, 43, 35, and 28 cases of laparoscopic left hemihepatectomy, left lateral hepatectomy, non-anatomic liver resection, and segmentectomy, respectively, the average operating time, blood loss, and hospitalization were almost the same as the overall mean results.

Conclusion The technique used in our center is a safe, fast, and effective approach to laparoscopic liver resection. Our 14 years of experience demonstrates that this technique can prevent postoperative bleeding and bile leakage. A surgeon can master the skill of laparoscopic left hemihepatectomy, left lateral hepatectomy, non-anatomic liver resection, and segmentectomy after $\sim 15-30,43,35$, and 28 case procedures, respectively.

Keywords Hepatectomy - Laparoscopy - Technique · Learning curve 
With the developments of medical technology and medical device innovation, surgical technology develops rapidly, especially in the field of abdominal surgery. Surgeons change techniques from traditional open surgery to modern laparoscopic methods, with the advent of robotic surgery allowing hands-free operating. Patient injury is decreasing. This trend toward minimally invasive surgery was an expected development.

In our Department of Hepatobiliary Surgery, laparoscopic liver resection is the best example of minimally invasive surgery. Surgeons have attempted to address the problem of intraoperative bleeding, which is the main problem in hepatectomy. In our opinion, the problem could be solved by developing brilliant instruments and techniques for transecting the liver parenchyma. The management of the raw liver surface is particularly important to prevent postoperative bleeding and bile leakage.

There are currently several methods used worldwide in laparoscopic hepatectomies: (1) Robles et al. [1] from Spain used the harmonic scalpel combined with the Ligasure Atlas for laparoscopic hepatectomy; (2) Liu et al. [2] from China used the harmonic scalpel combined with a bipolar coagulation in laparoscopy liver resection; and (3) Machado et al. [3] from Brazil invented the intrahepatic Glissonian approach in laparoscopic liver resection. A world review of laparoscopic liver resections through October 2009 by Nguyen et al. [4] reported that 2,804 patients in 127 articles underwent laparoscopic liver resection; the rate of bile leakage was $1.5 \%$, the rate of bleeding (including incisional bleed and intra-abdominal bleeding) was $0.89 \%$, the rate of all types of complications was $10.5 \%$, and mortality was $0.3 \%$. In our center, we used the 'curettage and aspiration' technique with laparoscopic Peng's multifunction operative dissector (LPMOD) and regional occlusion of inflow and outflow [5]. Currently, we have completed 365 cases of laparoscopic liver resection in the past 14 years using this method. The average operating time for these cases was $150 \pm 74 \mathrm{~min}$; average blood loss was $375 \pm 410 \mathrm{ml}$; rate of bile leakage after operation was $1.32 \%$; rate of postoperative bleeding was $0.66 \%$; rate of complications was $12.24 \%$; and no deaths have occurred. The results are even better in severe complications.

\section{Materials and methods}

\section{Patients}

From the first case in August 1998 to August 2012, we completed 365 consecutive cases of laparoscopic liver resection (160 males, 205 females; mean age $52 \pm 10$ years) with low complications and excellent results. We summarized our experience over 14 years of practice with the laparoscopic technique and management of the raw surface.

\section{Instruments}

We use LPMOD as our instrument for laparoscopic liver resection (illustrated in Fig. 1). It is an improvement on the PMOD invented by Professor Peng Shuyou with independent intellectual property rights [6]. LPMOD is more suitable to the laparoscopic technique. In 2008, we applied for a utility model patent on the instruments [7] and asked Zhejiang Shuyou Surgical Instrument Co., Ltd., in the Zhejiang Province of China, to manufacture them. LPMOD was made of an electric hollow metal tube and a control handle. At the head of the hollow tube is a slanted plane, and there are two buttons on the handle to control the LPMOD 'cut' and 'coag' buttons. The instrument may be connected to an aspirator. The LPOMD can cut and coagulate the tissues and suction the smoke and blood to provide a clear view. This minimizes the need to change instruments and saves a significant amount of time.

\section{Methods}

First, a plan was made for the range of liver resection based on history and imaging. A pneumoperitoneum was then established, and the abdomen was explored. To prevent ischemia reperfusion injury, the occlusion of the left/right inflow and outflow was performed instead of a total hepatic vascular occlusion (THVO). The left/right hepatic duct was clamped or cut off if possible. The key to selective regional hepatic vascular occlusion (RHVO) is the control of the three porta hepatis, as is described in Fig. 2 and Video 1. Blunt transection [8] was used to treat three porta hepatis. The laparoscopic technique facilitates treating the second/ third porta hepatis by allowing the surgeon to visualize the hepatic veins more clearly and clamp them more accurately. After regional occlusion of liver inflow and outflow, we could see the ischemic line on the liver surface (Fig. 3). Along this line, the liver parenchyma is transacted by LPMOD using the 'curettage and aspiration' technique [5]. There is almost no bleeding on the raw surface, which makes the procedure easier. The LPMOD can coagulate, cut and dissect the liver parenchyma, and suction blood or smoke. This minimizes the need to change instruments and saves a significant amount of time. The vessels and bile ducts dissected in the transection plane can be clamped by absorbed clips or Endo-GIA (more than $10 \mathrm{~mm}$ in diameter). Minor bleeding can be immediately coagulated by LPMOD. There is almost no bleeding and bile on the transection plane using this method (Fig. 4). After 
Fig. 1 LPMOD

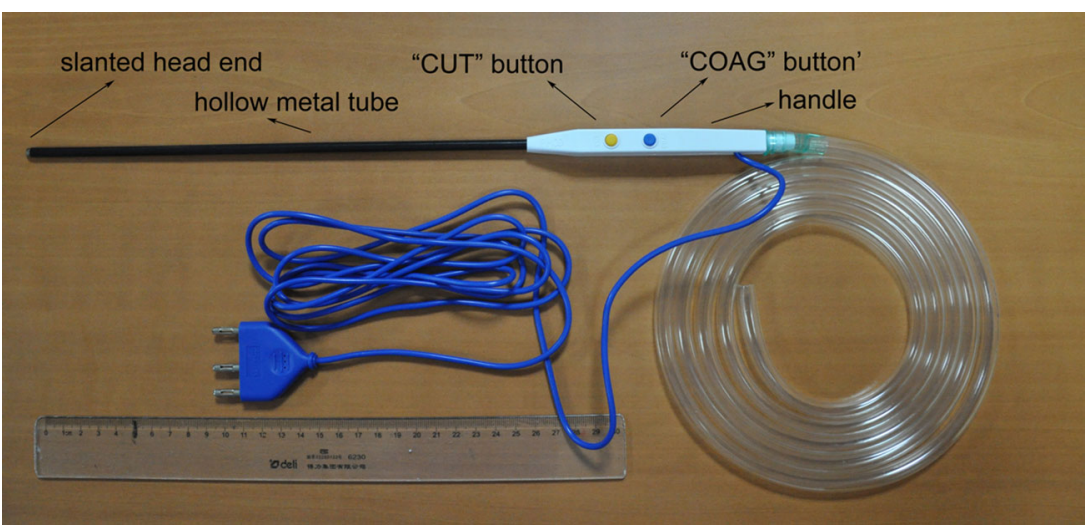

Fig. 2 Exposure and occlusion of hepatic inflow and outflow in laparoscopic liver resection.

A LHA and LHD, B left branch of the portal vein, clamped LHA and LHD, $\mathbf{C}$ right hepatic duct and right hepatic artery, $\mathbf{D}$ right branch of the portal vein,

E LHV and suprahepatic vena cava, $\mathbf{F}$ short hepatic veins and infrahepatic vena cava. $L H A$ left hepatic artery, $L H D$ left hepatic duct
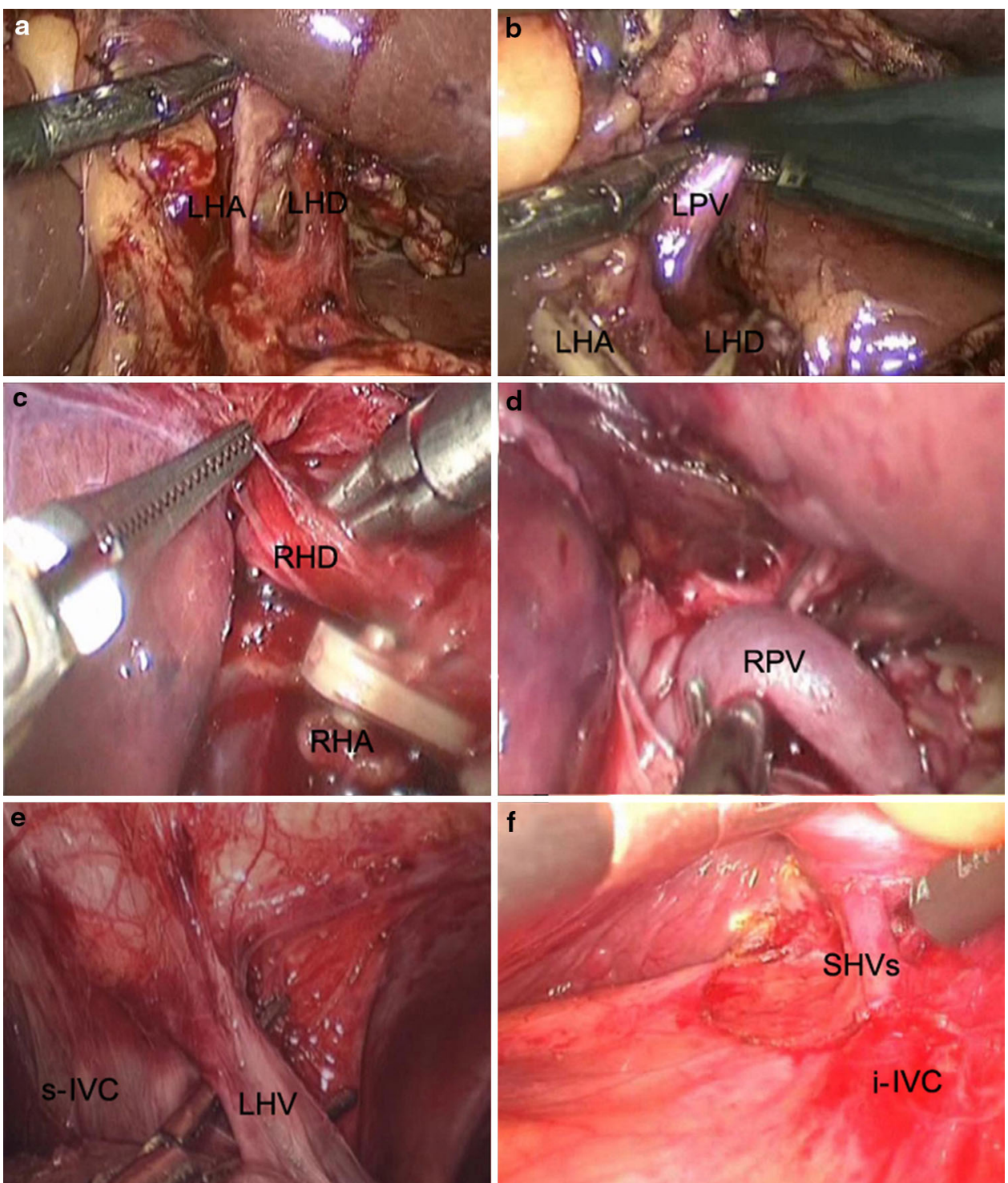

removing the resected liver, the raw surface was carefully coagulated inch by inch and then irrigated to confirm that there was no active bleeding. A drainage tube was placed near the transection plane.
The operative technique includes three points, summarized as follows: (1) regional occlusion of liver inflow and outflow; (2) use of the LPMOD; and (3) the 'curettage and aspiration' technique. There is a learning curve for new 
Fig. 3 Ischemic line on the surface of the liver under occlusion of hepatic inflow and outflow. A Under occlusion of the left inflow and outflow,

B under occlusion of the right inflow and outflow
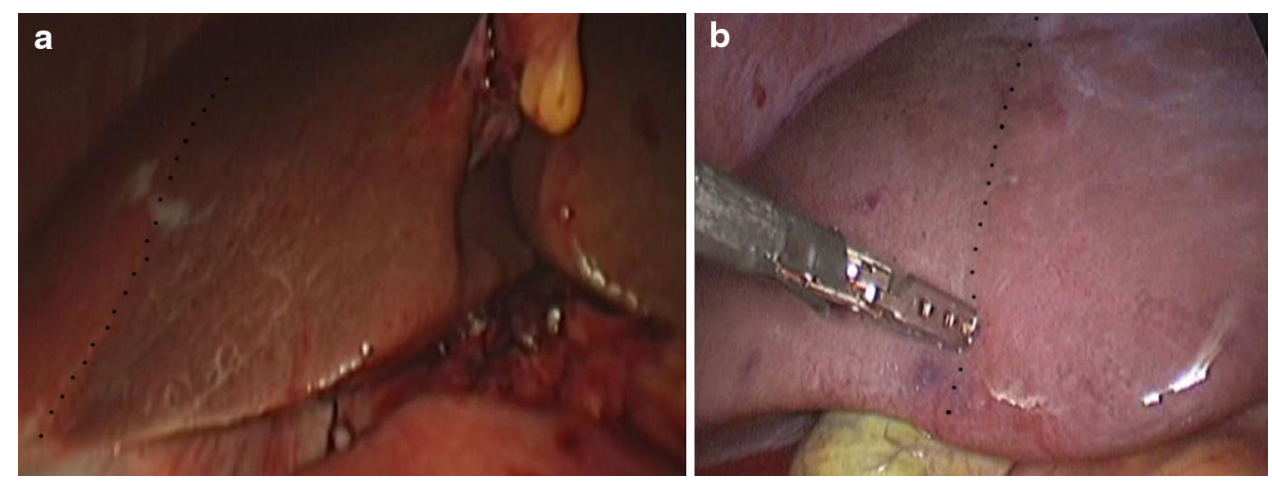

Fig. 4 Raw surface of laparoscopic liver resection
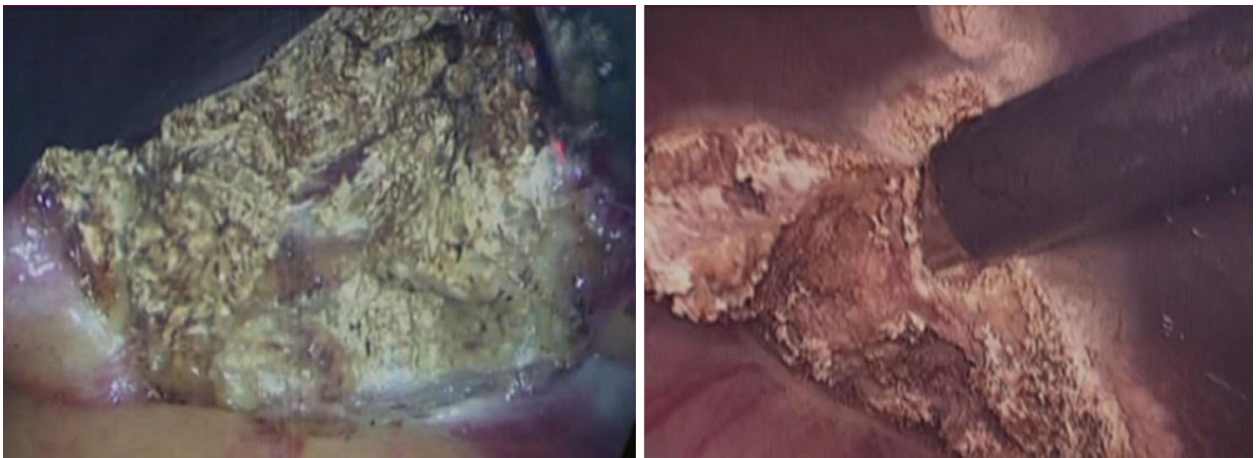

surgeons. Once the technique is mastered, it is a faster and safer way of liver resection. The raw surface is better handled, the eschar layer is thin, and more liver parenchyma can be retained, minimizing damage to the liver and allowing faster recovery of liver functions.

\section{Statistical analysis}

The data were statistically analyzed using the SPSS statistical software package, version 18 (SPSS, Inc., Chicago, IL, USA). The results are expressed as the mean \pm standard deviation values. The statistical significance of observed differences was tested by the $\chi^{2}$ test, Fisher's exact test, or $t$ test. A probability of 0.05 or less $(p<0$ 0.05 ) was considered statistically significant.

\section{Results}

We performed 365 cases (160 males, 205 females; mean age $52 \pm 10$ years) of laparoscopic liver resection, including left hemihepatectomy (80 cases), left lateral lobectomy (112 cases), non-anatomic hepatectomy (68 cases), segmental hepatectomy (35 cases), right hemihepatectomy, and caudate lobectomy. The diseases included liver cancer (99 cases), hepatolithiasis (120 cases), liver hemangioma, focal nodular hyperplasia, liver abscess, and metastatic hepatic carcinoma. In total, 63 cases $(17.20 \%)$ were converted to open surgery because of severe adhesions, bleeding, or anatomical limitation. Mean blood loss was $370.6 \pm 404.0 \mathrm{ml}$; mean operating time was $150.8 \pm 73.0 \mathrm{~min}$, and mean postoperative hospitalization (length of stay; LOS) was $9.2 \pm 5.3$ days. Four cases $(1.32 \%)$ had bile leakage, and two had hemorrhage $(0.66 \%)$. No intraoperative or postoperation deaths occurred (Table 1).

\section{Discussion}

Rationale of the methods

The 'curettage and aspiration' technique is an approach using Peng's multifunction operative dissector (PMOD), which was developed by Professor Peng after years of practice. It is safer and more efficient than other methods [9]. It has the same effect when PMOD are used in laparoscopic liver resection after lengthening the instrument head. This modified instrument is called the LPMOD [5]. During laparoscopic liver resection, the operator pulls the head of the LPMOD's sharp side from the top downwards to split the liver parenchyma. The transection plane is coagulated with the LPMOD while the first assistant maintains the tension between the transection line of the liver surface marked, based on preoperative imaging or intraoperative ultrasonography. The minor vessels and bile 
Table 1 Overview of laparoscopic liver resection in our single center

\begin{tabular}{lll}
\hline Item & Remarks & Results \\
\hline Male/female & & $160 / 205$ \\
Laparoscopic hepatectomy (case) & Left hemihepatectomy & 80 \\
& Left lateral sectionectomy & 112 \\
& Non-anatomic resections & 68 \\
& Segmentectomy & 35 \\
& Others (right hemihepatectomy, caudate lobectomy, & 11 \\
& radical resection of gallbladder cancer) & \\
Diseases (case) & Malignant tumors & 99 \\
& Hepatolithiasis & 120 \\
Converted to open surgery (\%) & Benign tumors (one case of liver abscess) & 146 \\
Blood loss (ml) & & 17.20 \\
Operating time (min) & & $370.6 \pm 404.0$ \\
Hospital stay (days) & & $150.8 \pm 73.0$ \\
Bile leakage (\%) & & $9.2 \pm 5.3$ \\
Bleeding (\%) & & 1.32 \\
Mortality (\%) & cases & 0.66 \\
Other complications (\%) & Ascites and pleural effusion, gastrointestinal & 0 \\
Total complications (\%) & dysfunction, incision infection, incisional hernia & 10.26 \\
\hline & & 12.24 \\
\hline
\end{tabular}

ducts are coagulated together with the liver parenchyma, larger vessels, and bile ducts that will be left because of their tenacity. These structures are clamped with clips or Endo-GIA (more than $10 \mathrm{~mm}$ in diameter). The LPMOD can aspirate liver fragments, blood, and smoke to keep the field of vision clear. The LPMOD is a multifunctional instrument that minimizes the need to change instruments and helps to save time. We control the inflow and outflow blood of part liver, which greatly reduces blood loss and avoids reperfusion injury to the remaining liver. This keeps the field of vision clear and helps the operation to run more smoothly and, most importantly, it prevents intraoperative hepatic vein rupture and air embolism.

\section{Learning curve}

To successfully finish the laparoscopic liver resection, it is necessary to master the RHVO and 'curettage and aspiration' technique, which are difficult to master. However, mastery is easier for hepatobiliary surgeons because they have performed many THVOs during open surgeries and simply need more practice with the laparoscopic technique. Surgeons must know the exact anatomy of the extrahepatic Glisson system in dealing with the first porta hepatis. Regarding the second and third porta of liver, the laparoscopic technique has the advantage of clear exposure. The 'curettage and aspiration' technique can be learned in open surgery, and surgeons can then attempt it in the laparoscopic approach. Although the technique is technically demanding, surgeons can learn it through study.

The annual total cases, conversion rate (laparoscopy to open hepatectomy), complication rate, average operating time, mean blood loss, and mean hospitalization (or LOS) for each type of laparoscopic liver resection in our center has been summarized in Tables 2, 3, 4 and 5 .

Table 2 shows the annual basic information for the laparoscopic left hemihepatectomy. We compared cases this year with the previous year for each item. For the left hemihepatectomy, mean operating time and mean blood loss were significantly lower in 2007 than in 2006 $(p<0.05)$. From 2007 on, mean operating time and mean blood loss were almost at the same level $(p>0.05)$. The conversion rate from laparoscopy to open surgery in 2008 was lower than in $2007(p<0.01)$. The complication rate and mean LOS had no significant differences between each year $(p>0.05)$. There were a total of 15 and 30 cases until 2006 and 2007, respectively, meaning a surgeon could master the skill of laparoscopic left hemihepatectomy after 15-30 procedures, according to our experience.

Table 3 shows the annual basic information for the laparoscopic left lateral hepatectomy. There were no significant differences when comparing each item this year with that of the previous year (i.e. 2007 vs. 2006, 2010 vs. 2009 , etc.). Mean blood loss in 2007 was remarkably lower than in 2006 ( $p>0.05$ ). From 2007 until 2012, mean blood loss was maintained at the same level, indicating that a 
Table 2 Basic information of laparoscopic left hemihepatectomy each year

\begin{tabular}{lllllrlr}
\hline Year & $\begin{array}{l}\text { Total no. } \\
\text { of cases }\end{array}$ & $\begin{array}{l}\text { Converted to } \\
\text { open }\end{array}$ & Open rate & $\begin{array}{l}\text { Complications rate } \\
\text { (bile leakage and bleeding) }\end{array}$ & $\begin{array}{l}\text { Mean operating } \\
\text { time (min) }\end{array}$ & $\begin{array}{l}\text { Mean blood } \\
\text { loss (ml) }\end{array}$ & $\begin{array}{l}\text { Mean LOS } \\
(\mathrm{days})\end{array}$ \\
\hline $1998-2006$ & 15 & 5 & 0.33 & 0.07 & $264.5 \pm 118.3$ & $590.0 \pm 292.3$ & $12.9 \pm 9.9$ \\
2007 & 15 & 7 & 0.47 & 0.07 & $178.8 \pm 37.0^{*}$ & $381.3 \pm 311.6^{*}$ & $12.5 \pm 5.7$ \\
2008 & 24 & 2 & $0.08^{* *}$ & 0.08 & $209.3 .7 \pm 47.9$ & $277.3 \pm 161.3$ & $12.6 \pm 4.2$ \\
2009 & 12 & 0 & 0 & 0.08 & $187.1 \pm 96.8$ & $253.3 \pm 127.0$ & $10.8 \pm 3.9$ \\
2010 & 13 & 1 & 0.08 & 0 & $177.5 \pm 56.7$ & $379.2 \pm 201.7$ & $11.4 \pm 5.1$ \\
2011 & 12 & 3 & 0.25 & 0 & $205.0 \pm 39.0$ & $294.4 \pm 137.9$ & $11.2 \pm 3.2$ \\
2012 & 7 & 0 & 0 & 0 & $203.6 \pm 51.2$ & $342.9 \pm 97.6$ & $8.3 \pm 2.5$ \\
\hline
\end{tabular}

LOS length of hospital stay

$* p<0.05 ;{ }^{* *} p<0.01$ compared with cases from the previous year

Table 3 Basic information of laparoscopic left lateral liver resection each year

\begin{tabular}{|c|c|c|c|c|c|c|c|}
\hline Year & $\begin{array}{l}\text { Total no. } \\
\text { of cases }\end{array}$ & $\begin{array}{l}\text { Converted to } \\
\text { open }\end{array}$ & Open rate & $\begin{array}{l}\text { Complications rate } \\
\text { (bile leakage and bleeding) }\end{array}$ & $\begin{array}{l}\text { Mean operating } \\
\text { time (min) }\end{array}$ & $\begin{array}{l}\text { Mean blood } \\
\text { loss }(\mathrm{ml})\end{array}$ & $\begin{array}{l}\text { Mean LOS } \\
\text { (days) }\end{array}$ \\
\hline 1998-2004 & 13 & 1 & 0.08 & 0.08 & $168.8 \pm 64.8$ & $625.0 \pm 628.3$ & $10.8 \pm 9.2$ \\
\hline 2005 & 15 & 1 & 0.07 & 0 & $165.0 \pm 51.9$ & $630.0 \pm 619.2$ & $7.6 \pm 2.8$ \\
\hline 2006 & 15 & 1 & 0.07 & 0 & $176.6 \pm 83.3$ & $439.3 \pm 315.1$ & $8.8 \pm 6.0$ \\
\hline 2007 & 17 & 2 & 0.12 & 0 & $141.2 \pm 57.9$ & $243.3 \pm 205.2$ & $7.9 \pm 4.0$ \\
\hline 2008 & 15 & 0 & 0 & 0 & $150.7 \pm 74.6$ & $217.3 \pm 100.2$ & $7.9 \pm 3.5$ \\
\hline 2009 & 8 & 0 & 0 & 0.25 & $131.9 \pm 43.8$ & $312.5 \pm 305.6$ & $10.3 \pm 8.4$ \\
\hline 2010 & 19 & 1 & 0.05 & 0.11 & $113.2 \pm 43.2$ & $230.6 \pm 135.2$ & $8.8 \pm 7.0$ \\
\hline 2011 & 15 & 3 & 0.2 & 0 & $105.0 \pm 32.1$ & $223.3 \pm 188.0$ & $10.0 \pm 3.8$ \\
\hline 2012 & 4 & 0 & 0 & 0 & $152.5 \pm 49.4$ & $175.0 \pm 50.0$ & $6.0 \pm 1.2$ \\
\hline
\end{tabular}

LOS length of hospital stay

Table 4 Basic information of laparoscopic non-anatomic liver resection each year

\begin{tabular}{lllllllr}
\hline Year & $\begin{array}{l}\text { Total no. of } \\
\text { cases }\end{array}$ & $\begin{array}{l}\text { Converted to } \\
\text { open }\end{array}$ & $\begin{array}{l}\text { Open } \\
\text { rate }\end{array}$ & $\begin{array}{l}\text { Complications rate (bile leakage } \\
\text { and bleeding) }\end{array}$ & $\begin{array}{l}\text { Mean operating } \\
\text { time (min) }\end{array}$ & $\begin{array}{l}\text { Mean blood } \\
\text { loss (ml) }\end{array}$ & $\begin{array}{l}\text { Mean LOS } \\
(\text { days })\end{array}$ \\
\hline $1998-2005$ & 12 & 2 & 0.17 & 0.17 & $131.5 \pm 50.7$ & $657.0 \pm 738.7$ & $10.0 \pm 5.3$ \\
2006 & 12 & 1 & 0.08 & 0.08 & $127.7 \pm 83.6$ & $582.7 \pm 737.6$ & $9.2 \pm 7.1$ \\
2007 & 11 & 3 & 0.27 & 0 & $116.4 \pm 44.5$ & $482.5 \pm 545.7$ & $8.0 \pm 3.7$ \\
2008 & 12 & 3 & 0.25 & 0 & $115.0 \pm 53.5$ & $234.4 \pm 202.0$ & $8.2 \pm 3.6$ \\
2009 & 9 & 2 & 0.22 & 0 & $82.9 \pm 33.3$ & $250.0 \pm 223.6$ & $7.9 \pm 6.4$ \\
2010 & 16 & 3 & 0.19 & 0 & $73.1 \pm 17.0$ & $107.7 \pm 103.1$ & $5.9 \pm 3.0$ \\
$2011-2012$ & 11 & 1 & 0.09 & 0 & $89.0 \pm 37.2$ & $137.0 \pm 97.3$ & $7.2 \pm 2.8$ \\
\hline
\end{tabular}

LOS length of hospital stay

Table 5 Basic information of laparoscopic liver segmentectomy each year

\begin{tabular}{llllllll}
\hline Year & $\begin{array}{l}\text { Total no. of } \\
\text { cases }\end{array}$ & $\begin{array}{l}\text { Converted to } \\
\text { open }\end{array}$ & $\begin{array}{l}\text { Open } \\
\text { rate }\end{array}$ & $\begin{array}{l}\text { Complications rate (bile leakage } \\
\text { and bleeding) }\end{array}$ & $\begin{array}{l}\text { Mean operating } \\
\text { time (min) }\end{array}$ & $\begin{array}{l}\text { Mean blood } \\
\text { Loss (ml) }\end{array}$ & $\begin{array}{l}\text { Mean LOS } \\
(\text { days })\end{array}$ \\
\hline $1998-2004$ & 10 & 0 & 0 & 0 & $129.0 \pm 44.3$ & $610.0 \pm 470.7$ & $8.1 \pm 2.6$ \\
$2005-2007$ & 18 & 8 & 0.44 & 0 & $166.0 \pm 101.4$ & $816.0 \pm 866.3$ & $7.0 \pm 3.5$ \\
$2008-2009$ & 8 & 3 & 0.38 & 0 & $125.0 \pm 37.6$ & $310.0 \pm 387.9$ & $7.8 \pm 4.3$ \\
$2010-2012$ & 13 & 3 & 0.23 & 1 & $92.2 \pm 39.6$ & $321.0 \pm 291.5$ & $7.3 \pm 5.7$ \\
\hline
\end{tabular}

LOS length of hospital stay 
surgeon could successfully finish a laparoscopic left lateral liver resection after $\sim 43$ cases (total cases until 2006).

Table 4 shows the annual basic information for laparoscopic non-anatomic liver resection. Non-anatomic liver resection means local resection, which was usually performed when the mass was small and located superficially in the liver. There was no significant difference when performing statistical analysis using the method in Table 3 . In 2008, mean blood loss declined and then plateaued. All of the other items, such as open rate, complications rate, mean operating time, and mean LOS, seem to have no significant difference, which shows that after performing 35 cases, a surgeon can master the skill of laparoscopic non-anatomic liver resection.

Table 5 shows the annual basic information for laparoscopic liver segmentectomy. There are not many cases of laparoscopic liver segmentectomy. We grouped several years together for statistic analysis. After 28 cases (i.e. until 2007), mean operating time and mean blood loss decreased rapidly, although there was no statistical significance $(p>0.05)$. For a laparoscopic liver segmentectomy, a surgeon needs $\sim 28$ cases for training.

There are too few cases of other procedures, such as right hemihepatectomy and caudate lobectomy, to perform a statistical analysis, therefore we did not take these into account.

\section{Safety analysis}

After a systematic training program, the safety and success rate increased greatly in laparoscopic liver resection [10]. Because almost no bleeding occurs in the transection plane using our technique, surgeons can address the bile ducts and vessels carefully and confidently. In some cases, it is impossible to finish RHVO. When the left hepatic vein (LHV) is located in the liver parenchyma, it can form an extrahepatic common stem with the middle hepatic vein (MHV), which cannot be occluded. Familiarity with some common hepatic vessel variations help to increase the success and safety rates of laparoscopic hepatectomy. The portal vein, hepatic artery, and hepatic vein have rich blood perfusion; thus, they must be handled with extreme care, or there will be excessive bleeding that greatly increases the operation risk. In our center, mean blood loss was $370.6 \pm 404.0 \mathrm{ml}$, the rate of postoperative bile leakage was $1.32 \%$, and the rate of postoperative bleeding was $0.66 \%$. No deaths occurred. The total complication rate, including bile leakage, bleeding, ascites and pleural effusion, gastrointestinal dysfunction, incision infection, and incisional hernia, was $12.24 \%$. Mean blood loss of each procedure decreased each year (Tables $2,3,4,5$ ). We consider this technique to be a safe method of laparoscopic hepatectomy.

\section{Practicability}

As the worldwide popularity of laparoscopic hepatectomy gradually increases, the indications for this procedure expand, and some primary hospitals are performing this procedure, which makes the practicality of our technique important. From a cost standpoint, the procedure only requires the LPMOD. Unlike the Harmonic scalpel, EndoGIA, Argon beam coagulator, Ligasure, and microwave coagulator, the LPMOD is inexpensive and multifunctional (Table 6). It is a low-cost, high-efficiency instrument. The method is technically demanding, and surgeons who wish to use this technique will experience a learning curve. As mentioned above, after systematic trainings, surgeons should be able to master the technique completely, making the technique more practical.

\section{Advantages}

After years of practice, we find several advantages of our technique, including the following: (1) economic-one LPMOD can perform laparoscopic hepatectomy in a minimally invasive surgery hospital, saving medical resources; (2) time saving - it is fast and complete to transect the liver, which saves operative time and reduces the risks related to prolonged anesthesia; (3) less blood loss and

Table 6 Price and functions of the main instruments used in laparoscopic liver resection

\begin{tabular}{|c|c|c|c|c|c|}
\hline \multirow[t]{2}{*}{ Instruments } & \multirow[t]{2}{*}{ Price (RMB) } & \multicolumn{4}{|l|}{ Functions } \\
\hline & & Dissection & Coagulation & Aspiration & Cut \\
\hline LPMOD & 200 & + & + & + & + \\
\hline Argon beam coagulator & $300,000-500,000$ & - & + & - & - \\
\hline Harmonic scalpel & $700,000-1,000,000$ & + & + & - & + \\
\hline Microwave & $1,000,000-1,500,000$ & - & + & - & - \\
\hline Ligasure & $500,000-1,000,000$ & + & + & - & + \\
\hline Endo-GIA & 3,800/times & - & - & - & + \\
\hline
\end{tabular}

$R M B$ Chinese Renminbi, $L P M O D$ laparoscopic Peng's multifunctional operational dissectors 
prevention of gas embolism-the regional occlusion of inflow and outflow minimize bleeding and prevents gas embolism during procedures; (4) minimal harm-only slight damage is done to the transection plane, the eschar layer is thinner than when transected by other instruments so as to maintain more liver parenchyma, and the recovery of hepatic function after surgery is more rapid; (5) safetythis method clearly shows the blood vessels and bile ducts when transecting the liver and allows them to be completely and precisely clamped under direct vision instead of blindly addressed. This makes the procedure safer and reduces the incidence rate of postoperative bleeding and bile leakage on the transection surface.

\section{Disadvantages}

Surgeons who use this method must have extensive experience in open hepatectomy and will experience a learning curve, especially in the occlusion of inflow and outflow. RHVO is extremely dangerous once a laparoscopic hepatectomy has failed. Additionally, LPMOD needs two people to operate it; in addition to the main operator, an assistant is needed to control the suction with vascular forceps. We have invented a new instrument that can be operated by one surgeon.

\section{Conclusion}

In conclusion, the technique used in our center is a safe, fast, and effective method for laparoscopic liver resection and management of the raw surface. Based on the findings from our 14 years of experience, it can prevent postoperative bleeding and bile leakage. A surgeon can master the skill of laparoscopic left hemihepatectomy, left lateral hepatectomy, non-anatomic liver resection and segmentectomy after $\sim 15-30,43,35$, and 28 case procedures, respectively. We hope that this technique will increase in popularity.
Disclosures Xiujun Cai, Zheyong Li, Yale Zhang, Hong Yu, Xiao Liang, Renan Jin, and Feng Luo have no conflicts of interest or financial ties to disclose.

Open Access This article is distributed under the terms of the Creative Commons Attribution License which permits any use, distribution, and reproduction in any medium, provided the original author(s) and the source are credited.

\section{References}

1. Robles R, Marín C, Abellán B, López-Conesa A, Ramírez P, Parrilla P (2006) Right hepatectomy and left hepatectomy performed via hand-assisted laparoscopic surgery. Description of an original technique (in Spanish). Cir Esp 80:326-330

2. Liu R, Huang ZQ, Zhou NX, Huang XQ, Wang YH, Jiang K, Xiang X (2004) Operational line of laparoscopic liver resections. Zhonghua Yi Xue Za Zhi 84:219-221

3. Machado MA, Surjan RC, Makdissi FF (2011) Intrahepatic glissonian approach for pure laparoscopic right hemihepatectomy. Surg Endosc 25:3930-3933

4. Nguyen KT, Gamblin TC, Geller DA (2009) World review of laparoscopic liver resection: 2,804 patients. Ann Surg 250: 831-841

5. Cai XJ, Yu H, Liang X, Wang YF, Zheng XY, Huang DY, Peng SY (2006) Laparoscopic hepatectomy by curettage and aspiration: experiences of 62 cases. Surg Endosc 20:1531-1535

6. Peng SY (1994) Multifunctional operational dissectors. China Patent CN1080512

7. Peng SY, Su Y, Cai XJ (2007) Operational dissectors. China Patent CN3671884

8. Cai XJ, Gu XJ, Wang YF, Yu H, Liang X (2007) Experience in laparoscopic cholecystectomy by exposing common hepatic duct using blunt dissection to prevent bile duct injury. Zhonghua Yi Xue Za Zhi 87:1425-1426

9. Peng SY, Li JT, Mou YP, Liu YB, Wu YL, Fang HQ, Cao LP, Chen L, Cai XJ, Peng CH (2003) Different approaches to caudate lobectomy with "curettage and aspiration" technique using a special instrument PMOD: a report of 76 cases. World J Gastroenterol 9:2169-2173

10. Cai XJ, Wang YF, Liang YL, Yu H, Liang X (2009) Laparoscopic left hemihepatectomy: a safety and feasibility study of 19 cases. Surg Endosc 23:2556-2562 